\title{
PEMBERDAYAAN KELOMPOK WANITA TANI DESA KARANG SIDEMEN MELALUI PENGOLAHAN KERIPIK PISANG DALAM UPAYA MENINGKATKAN TARAF EKONOMI MASYARAKAT
}

\author{
I Wayan Suana ${ }^{1}$, Baiq Rahmayanti ${ }^{2}$, Malhatun $^{3}$, R. Tuti Yulistiana ${ }^{4}$ \\ ${ }^{1}$ Fakultas Matematika dan IImu Pengetahuan Alam, Universitas Mataram. \\ ${ }^{2}$ Fakultas Teknologi Pangan dan Agroindustri, Universitas Mataram. \\ ${ }^{4}$ Fakultas Ekonomi dan Bisnis, Universitas Mataram. \\ ${ }^{3}$ Fakultas Keguruan dan IImu Pendidikan, Universitas Mataram.
}

\begin{abstract}
ABSTRAK. Kesejahteraan masyarakat dapat diupayakan dengan memberdayakan dan memandirikan masyarakat dalam kehidupan ekonominya. Hal ini dilakukan dengan membangun daya dan tenaga yang dimiliki masyarakat melalui motivasi untuk membangkitkan kesadaran masyarakat akan potensi yang dimiliki serta berusaha untuk bisa mengembangkan potensi dan sumber daya yang ada. Maksud dan tujuan dari penelitian ini yaitu untuk memberdayakan masyarakat Desa Karang Sidemen agar dapat meningkatkan perekonomian melalui pengolahan produk pertanian yaitu buah pisang menjadi keripik pisang. Pengembangan agroindustri pisang dengan mengolahnya menjadi keripik pisang, diharapkan mampu meningkatkan pendapatan petani, meningkatkan kesempatan kerja, kesempatan berusaha di pedesaan, meningkatkan nilai tambah, dan meningkatkan mutu produk pisang
\end{abstract}

Kata Kunci: pemberdayaan, potensi, Karang Sidemen, keripik pisang.

ABSTRACT. Community welfare can be pursued by empowering and independence of the community in their economic lives. This is done by building the power and energy possessed by the community through motivation to raise public awareness of their potential and try to be able to develop the potential and available resources. The purpose and objective of this study is to empower the Karang Sidemen Village community to improve the economy through the processing agricultural products, namely bananas into banana chips. The development of banana agro-industry by processing it into banana chips, is expected to increase farmers' income, increase employment opportunities, business opportunities in the countryside, increase added value, and improve the quality of banana products.

Keyword: empowerment, potency, Karang Sidemen, banana chips.

\section{PENDAHULUAN}

Kesejahteraan masyarakat dapat diupayakan dengan memberdayakan dan memandirikan masyarakat dalam kehidupan ekonominya. Hal ini dilakukan dengan membangun daya dan tenaga yang dimiliki masyarakat melalui motivasi untuk membangkitkan kesadaran masyarakat akan potensi yang dimiliki serta berusaha untuk bisa mengembangkan potensi dan sumber daya yang ada. Pada hakikatnya masyarakat dapat berkembang sesuai dengan potensi yang dimilikinya. Oleh karena itu, usaha pemberdayaan masyarakat mensyaratkan keterlibatan masyarakat mulai dari perencanaan, pelaksanaan, maupun pada saat monitoring dan evaluasi. Hal ini dimaksudkan 
supaya menjadi subyek proses perencanaan dan mampu berkembang secara mandiri, keberlanjutan sebagai unit sosial maupun ekonomi yang otonom (Anwar et al 2017).

Pemberdayaan masyarakat pada dasarnya merupakanstrategi perubahan sosial secara terencana yang diajukan untuk mengatasai masalah atau memenuhi kebutuhan masyarakat. Dalam proses pemberdayaan, masyarakat mendapatkan pembelajaran agar dapat secara mandiri melakukan upaya- upaya perbaikan kualitas kehidupannya. Dengan demikian proses tersebut harus dilaksanakan dengan adanya keterlibatan penuh masyarakat itu sendiri secara bertahap, terusmenerus, dan berkelanjutan (Saugi dan Sumarno, 2015).

Desa Karang Sidemen memiliki potensi pertanian yang salah satunya adalah buah pisang.Setiap panen produksinya melimpah sehingga mengakibatkan harga jualnya rendah. Hal ini disebabkan karena kurangnya pengetahuan masyarakattentang pengolahan lebih lanjut mengenai buah pisang, sehingga memiliki nilai ekonomi lebih tinggi. Sebagian masyarakat telah membuat produk olahan dari buah pisang salah satunya keripik pisang, namun hanya sebatas produksi rumahan yang dijual langsung kepengepul tanpa label dan kemasan yang memadai. Ini mengakibatkan nilai jual yang rendah dan keuntungan yang rendah pula. Kurangnya strategi pemasaran juga mengakibatkankurang berkembangnya usaha keripik pisang di Desa Karang Sidemen.

Selain masalah pemasaran dan pelabelan, kelompok usaha yang ada di Desa Karang Sidemen juga banyak yang belum memiliki surat izin dagang, No. P-IRT, No. BPOM dan halal LPPOM MUI sehingga pemasarannya pun terbatas. Melihat potensi Sumber Daya Alam (SDA) khususnya dalam bidang pertanian di Desa Karang Sidemen menjadi daya tarik bagi KKN Tematik Universitas Mataram 2019 untuk mengoptimalkan dan melaksanakan diversifikasi pangan sekaligus pemberdayaan masyarakat khususnya perempuan untuk dapat meningkatkan perekonomian masyarakat. Oleh karena itu, KKN Tematik Universitas Mataram Tahun 2019 melakukan mitra kerja dengan Kelompok Wanita Tani (KWT) "Kaki Rinjani" untuk melakukan diversifikasi produk berupa pengolahan produk pertanian yaitu buah pisang menjadi keripik pisang. Pengembangan agroindustri pisang dengan mengolahnya menjadi keripik pisang, diharapkan mampu meningkatkan pendapatan petani, meningkatkan kesempatan kerja, kesempatan berusaha di pedesaan, meningkatkan nilai tambah, dan meningkatkan mutu produk pisang (Putri et al 2012).

\section{METODE}

Kegiatan ini dilaksanakan di Desa Karang Sidemen, Kecamatan Batukliang Utara, Kabupaten Lombok Tengah pada bulan Februari - Maret 2019. Adapun tahapan pelaksanaan kegiatan dijabarkan dalam pemaparan sebagai berikut.

\section{Tahap 1. Persiapan Program KKN Tematik Unram}

\section{Menyusun Rencana Operasional Kegiatan}

Dalam tahap ini tim KKN Tematik Unram, menyusun rencana mulai dari rencana rapat koordinasi tim, surat menyurat, mengidentifikasi kriteria, jumlah instruktur/pendamping, jadwal kegiatan, pelaksanaan program pelatihan dan pendampingan, pelaksanaan monitoring dan evaluasi, serta rencana penyusun laporan kegiatan kemudian penulisan artikel sebagai hasil luaran dari program KKN Tematik Unram 


\section{Melaksanakan Rapat Koordinasi Tim Pelaksana}

Dalam tahap ini tim KKN Tematik Unram melaksanakan rapat pembagian tugas tim, mengagendakan rapat koordinasi, yang ditujukan agar pelaksanaan kegiatan mulai dari persiapan, pelaksanaan, monitoring dan evaluasi, sampai pada pembuatan dan penyusunan laporan serta penulisan artikel dapat berjalan sesuai dengan rencana yang telah ditetapkan.

Perekrutan dan pembentukan Kelompok Wanita Tani (KWT)

Dalam perekrutan dan pembentukan Kelompok Wanita Tani (KWT) di Desa Karang Sidemen, tim KKN Tematik Unram bekerjasama dengan pengelola dan produsen Kelompok Wanita Tani (KWT) "Kaki Rinjani" dalam menyiapkan Materi pembekalan yang akan di sampaikan kepada ibuibu KWT mengenai materi yang berkenaan dengan permasalahan yang di hadapi di bidang pengembangan usaha kecil yaitu: Materi tentang kualitas produksi (manajemen Produksi), Materi tentang standar-standar pembuatan produk kripik pisang, Materi tentang Manajemen Usaha dan administrasi Keuangan, materi tentang merek (Branding) usaha kecil, Materi tentang desain packaging (kemasan produk), dan Materi tentang teknik pemasaran online dan offline (ecommers). Materi tersebut di atas diberikan ibu- ibu KWT dengan harapan ibu-ibu tersebut dapat memiliki bekal ketika mereka melakukan pendampingan kepada Mitra.

\section{Tahap 2. Pelaksanaan Kegiatan}

Dalam tahap pelaksanaan kegiatan ini dibagi menjadi beberapa sub kegiatan yaitu:

Kegiatan Pelatihan

Kegiatan pelatihan dilaksanakan di Dusun Persil Desa Karang Sidemen pada tanggal 1 Februari 2019. Kegiatan ini dihadiri oleh perwakilan ibu-ibu Desa Karang Sidemen dari ke- 14 Dusun. Untuk mengefektifkan kegiatan tersebut metode yang digunakan dalam pelatihan adalah menggunakan metode praktis sesuai kebutuhan mitra yang berupa kombinasi ceramah dan praktek. Adapun pelatihan yang diberikan diantaranya: manajemen usaha, penetapan harga pokok penjualan, pemasaran on line, packaging (kemasan produk), higienitas pengelolaan produksi makanan.

Kegiatan Pendampingan.

Dalam pendampingan, KKN Tematik UNRAM melaksanakan bimbingan langsung dilapangan/tempat usah sekaligus melakukan evaluasi terhadap hasil dari pelatihan aspekaspek dari aktivitas usaha industri Pengolahan keripik pisang.

\section{Pemasaran}

Dalam siklus pemasaran, tim KKN Tematik UNRAM melakukan pemasaran secara online (melalui social media masing-masing anggota KKN Tematik UNRAM 2019) maupun offline (KKN Tematik Unram 2019 terjun langsung ke pasaryakni di kedai-kedai, angkringan dan kantor KPU).

Monitoring dan Evaluasi

Program Evaluasi dilakukan secara bertahap, yaitu: evaluasi kegiatan harian, mingguan dan evaluasi Akhir. Evaluasi harian dilaksanakan oleh seluruh Anggota KKN Tematik UNRAM demi kelancaran program-program kerja selanjutnya, kemudian Kegiatan Mingguan 
dilakukan rutin seriap akhir pekan untuk mengetahui sampai mana program kerja yang sudah terlaksana dan program-program kerja yang belum terlaksana. Sedangkan untuk Evaluasi Akhir dilakukan pada saat akhir kegiatan yang diikuti oleh mahasiswa, dosen pendamping, aparat pemerintah desa.

\section{HASIL DAN PEMBAHASAN}

Pemberdayaan masyarakat dalam penelitian ini dilakuan kepada perempuan-perempuan yang ada di Desa Karang Sidemen. Mayoritas masyarakat Desa Karang Sidemen bekerja sebagai petani dan peternak, sehingga sangat bergantung dengan hasil panen. Sentra pengolahan keripik pisang di Desa Karang Sidemen terletak di Dusun Persil yakni Kelompok Wanita Tani (KWT) "Kaki Rinjani” yang ketuai oleh Ibu Hakiah. Jumlah anggota KWT ini terbatas sehingga produktivitas pengolahan keripik pisang masih rendah. Selain itu, Kelompok Wanita Tani (KWT) juga belum dapat melakukan promosi dan pemasaran produk secara maksimal. Oleh karena itu, melalui program Kuliah Kerja Nyata (KKN) ini diharapkan dapat memberikan solusi dan bimbingan terhadap permasalahan yang ada sehingga kedepannya produktivitas produk keripik berbahan dasar pisang ini dapat meningkat dan memiliki pangsa pasar yang luas.

Berdasarkan permasalahan yang ada KKN tematik UNRAM 2019 membentuk dan merekrut Kelompok Wanita Tani (KWT) dari ke-14 dusun yang ada di desa Karang Sidemen guna untuk menciptakan Kelompok Wanita Tani (KWT) baru agar bertambahnya produsen pengolahan keripik pisang. Berdasarkan hasil pertemuan yang telah dilaksanakan di Desa Karang Sidemen pada tanggal 1 Februari 2019 dengan ibu-ibu dari ke-14 dusun untuk membahas tentang maksud dan tujuan dari program kerja KKN tematik UNRAM 2019 serta perekrutan anggota Kelompok Wanita Tani (KWT). Luaran dari pertemuan yang diadakan yakni terbentuknya kelompok baru pada masingmasing dusun sehingga mereka dapat membentuk anggota dari masing-masing kelompok.

\section{Pengolahan dan Peningkatan Nilai Tambah Agroindustri Pisang}

Pengembangan agroindustri keripik pisang di Desa Karang sidemen dilakukan untuk meningkatkan taraf hidup masyarakat dan sebagai salah satu langkah pemanfaatan Sumber Daya Alam (SDA) dan meningkatkan Sumber Daya Manusia (SDM). Jenis pisang yang dapat digunakan sebagai keripik pisang yaitu pisang kepok, pisang reket, pisang sambelia, pisang mas, pisang ketip dan pisang tembaga. Pisang yang dibudidayakan sendiri di kebun masing-masing sangat melimpah, biasanya petani menjual pisang ketika sudah tua dengan harga jual yang terbilang murah. Dengan adanya agroindustri yang dibentuk dapat merubah nilai jual dari buah pisang dengan cara diversifikasi. Pengertian diversifikasi pangan mencakup konteks produksi, ketersediaan dan konsumsi pangan, Suhardjo (1998) dalam Hardono (2014). Salah satu aspek diversifikasi pangan yakni sebagai aspek produksi yang mendorong pengembangan berbagai ragam produksi pangan, dan menumbuhkan beragam usaha pengolahan pangan (rumah tangga, UMKM dan swasta (BKP, 2012). Desa Karang Sidemen memiliki UMKM yang bergerak dalam bidang pengolahan pangan yakni Kelompok Wanita Tani "Kaki Rinjani” serta UMKM yang bergerak dalam bidang kerajinan bambu yakni Kelompok Wanita Tani “Insan Mandiri”.

Pengolahan pisang menjadi keripik pisang dilakukan sepenuhnya oleh pengusaha melalui perekrutan tenaga kerja, investasi faktor tetap, dan biaya variabel untuk berproduksi, kegiatan pengolahan, melakukan diversifikasi produk sekaligus meningkatkan harga jual pisang sebagai resiko pertambahan nilai produk. Pada aspek permodalan, pengusaha lebih banyak berinteraksi 
dengan lembaga keuangan formal seperti bank (Hardono, 2014). Berbeda dengan pengolahan pisang menjadi keripik pisang yang dilakukan oleh Usaha Mikro, Kecil dan Menengah (UMKM) yakni melalui pembentukan kelompok, menetapkan struktur organisasi kelompok, menetapkan biaya varibael untuk berproduksi serta permodalan bersumber dari bantuan pemerintah melalui program pelatihan dan training. Membentuk agroindustri secara berkelompok dapat membentuk kerja sama dan kekompakan yang baik antar masyarakat sehingga dapat mensejahterakan kelompok dan memajukan Desa. Pelatihan Pengolahan Keripik Pisang

Pelatihan pengolahan keripik pisang bertujuan untuk memberdayakan warga perempuan desa. KKN tematik UNRAM 2019 mengadakan hubungan mitra kerja dengan ketua Kelompok Wanita Tani (KWT) "Kaki Rinjani”. Pelatihan pengolahan keripik pisang dilaksanakan pada tanggal 7 Februari 2019 dengan narasumber dari salah satu produsen keripik pisang Kelompok Wanita Tani (KWT) "Kaki Rinjani" berlokasi di sekretariat Kelompok Wanita Tani (KWT) "Kaki Rinjani", Dusun Persil, Desa Karang Sidemen. Pelatihan ini diadakan oleh KKN tematik UNRAM 2019 yang bertujuan agar peserta pelatihan dapat mengaplikasiakan kembali tata cara pengolahan keripik pisang yang sesuai dengan standar dari Kelompok Wanita Tani (KWT) "Kaki Rinjani”.

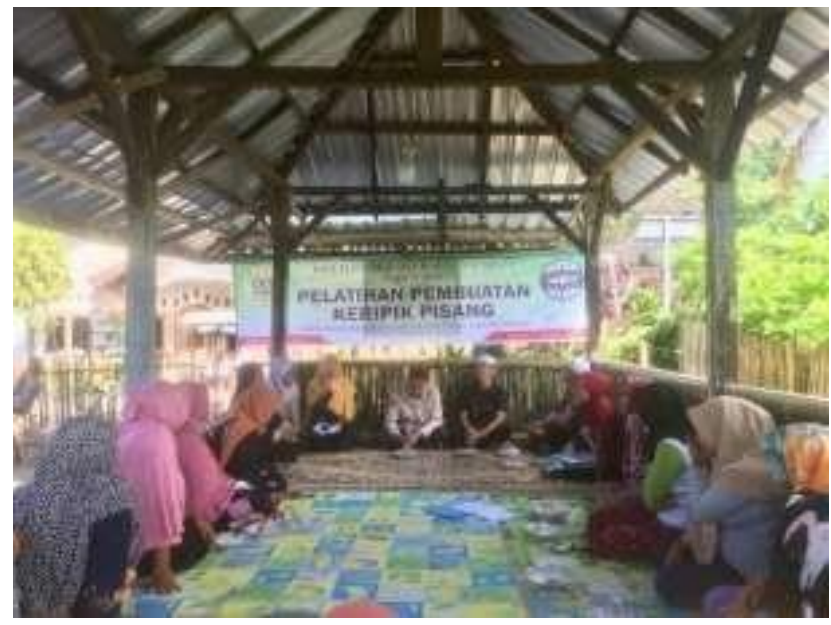

Gambar 1. Pelaksanaan Pelatihan Pengolahan Keripik Pisang

Proses pengolahan keripik pisang meliputi pengupasan, perajangan, pencucian/perendaman, pemberian pemanis dan pewarna (tidak dilakukan oleh semua produsen), dan penggorengan. Tiap tahapan dilakukan oleh anggota kelompok sampai pengemasan dan pemasaran. Pada beberapa Industri Rumah Tangga (IRT) yang ada di Desa Karang Sidemen terdapat salah satu IRT yang mengerjakan pembuatan keripik pisang (dari pengupasan hingga penggorengan) saja kemudian di jual kepada produsen lain dan membentuk label sendiri menggunakan produk dari IRT yang ada di Desa Karang Sidemen. 

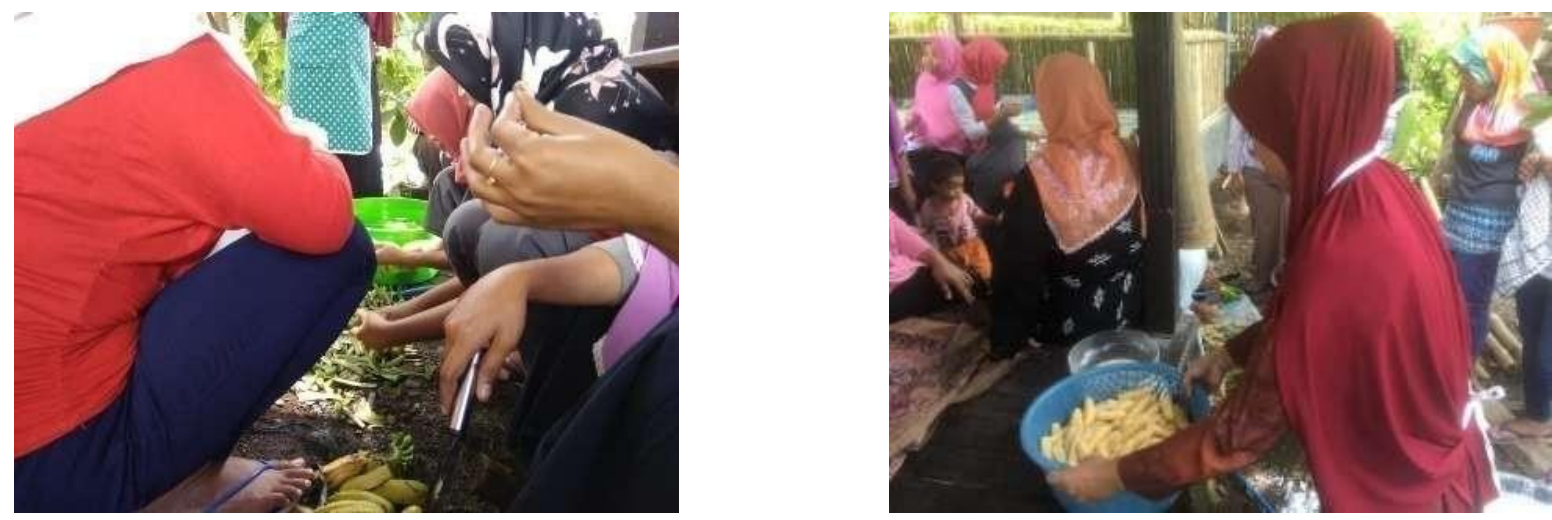

Gambar 2. Proses Pengupasan Buah Pisang (kiri) dan Proses Pembersihan Buah Pisang (Kanan).
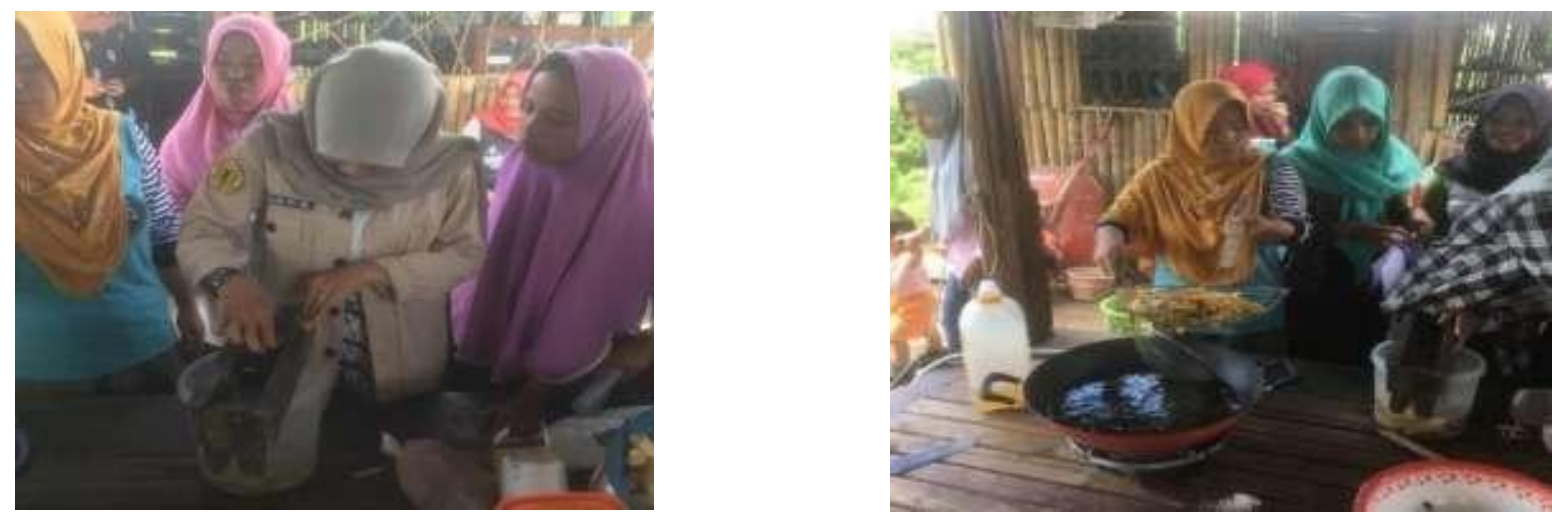

Gambar 3. Proses Perajangan (kiri) dan Proses Penggorengan Pisang (Kanan).

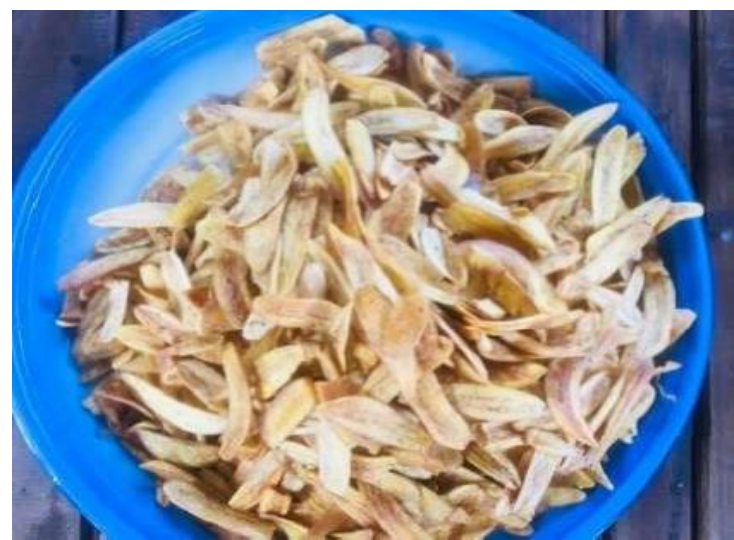

Gambar 4. Keripik Pisang "TELAPAH” Siap Kemas.

Kelompok Wanita Tani (KWT) "Kaki Rinjani” dan produsen lain yang ada di Desa Karang Sidemen biasanya membuat keripik pisang dari pisang sambelia dan pisang mas, dikarenakan harga jual buah pisang yang murah dan terjangkau. Untuk pisang kepok, pisang ketip dan pisang tembaga sebelumnya belum pernah dijadikan keripik pisang karena harga jual buah pisang yang terbilang cukup mahal. Mahalnya bahan baku menjadi kendala dalam upaya meningkatkan 
kualitas keripik pisang karena apabila bahan yang digunakan terlalu mahal maka harga jual pun menjadi meningkat dan akan memakan banyak modal sehingga keuntungan menjadi sedikit. Sedangkan jenis pisang reket ini dapat merusak minyak. Berdasarkan pengalaman dari para produsen keripik pisang yang ada di Desa Karang Sidemen pisang reket membuat minyak goreng yang digunakan menjadi hitam sehingga untuk pembuatan keripik pisang tidak pernah dilakukan menggunakan bahan pisang reket.

Untuk memenuhi persyaratan yang diberikan oleh KWT Kaki Rinjani, anggota KWT baru harus memenuhi standar kualitas yang diberikan oleh KWT Kaki Rinjani. Adapun standar keripik pisang dari KWT Kaki Rinjani yakni : 1) Pisang yang dapat digunakan sebagai keripik pisang yaitu pisang sambelia dan pisang mas. 2) Diameter irisan pisang harus sedikit lebih tebal agar supaya apabila irisan pisang digoreng tidak menjadi keriting dan cepat remuk. 3) Tidak diperbolehkan menggunakan pewarna sintetis dan perisa sintetis. Dari segi ukuran, pisang mas lebih kecil dari pisang sambelia sehingga untuk jenis kemasannya dibedakan karena harga jualpun berbeda. Kelompok baru diberikan keringanan oleh KWT Kaki Rinjani dengan diperbolehkannya menggunakan pemanis dan pewarna makanan namun dalam takaran yang dianjurkan dengan kemasan harga jual eceran seribuan.

Seperti yang telah dijelaskan mengenai permasalahan yang dikemukakan, KKN Tematik UNRAM 2019 ingin mencapai target yakni dapat me-management Kelompok Wanita Tani (KWT) baru agar dapat memproduksi keripik pisang dan dapat menggunakan label dari mitra kerja yakni Kelompok Wanita Tani (KWT) "Kaki Rinjani” dengan standar yang telah ditentukan sehingga produk keripik pisang dapat dipasarkan melalui satu pintu yaitu Kaki Rinjani dan permasalahan dalam pemasaran dapat direalisasikan. Namun hasil produksi keripik pisang yang diolah oleh KWT baru belum ada yang memenuhi standar KWT Kaki Rinjani dikarenakan masih baru mencoba sedangkan untuk menyamakan kualitas keripik pisang dengan KWT Kaki Rinjani memang harus banyak mencoba dan berlatih. Keripik pisang yang dihasilkan oleh KWT baru tetap dipasarkan dalam bentuk kemasan eceran seribu-an.Management pemasaran dalam hal ini berkaitan dengan target pasar. Jika pasar yang dituju masyarakat ekonomi kelas bawah maka produk dengan kemasan tanpa label dapat dipasarkan tanpa ada kritikan mengenai kemasannya, namun apabila pasar yang dituju masyarakat ekonomi kelas menengah dan atas maka produk yang dipasarkan harus memenuhi standar karena biasanya produk tersebut dipasarkan di supermarket ataupun di toko oleh-oleh dan toko-toko lainnya yang mengedepankan keamanan. Produk pangan yang aman dapat dilihat dari kemasannya yang telah memiliki surat izin dagang, No. P-IRT, No. BPOM dan halal LPPOM MUI. Hal ini menandakan suatu produk telah diuji dari segi higienitas dan kehalalan oleh pihak yang berwenang.

\section{Pengemasan dan Pemasaran Produk Keripik Pisang TELAPAH}

Pengemasan produk sebelumnya menggunakan label dari design Kelompok Wanita Tani (KWT) "Kaki Rinjani”. Brand yang digunakan yakni Keripik Pisang MAMI lengkap dengan labeling No. BPOM, No. P-IRT dan halal LPPOM MUI. Dengan adanya mitra kerja dengan KKN Tematik UNRAM 2019 Desa Karang Sidemen, KWT Kaki Rinjani sepakat untuk merubah nama atau brand kemasan. Hal ini dikarenakan brand MAMI sebelumnya telah terdaftar sebagai milik produsen lain. Tujuan perubahan brand itu sendiri dimaksudkan untuk mengangkat pariwisata danau biru sehingga yang diharapkan dari produk ini sebagai brand image oleh-oleh khas danau biru Desa Karang Sidemen. Brand baru yang ditawarkan yaitu keripik pisang TELAPAH (TELAngan 
laPAH), hal ini sejalan dengan kopi TELAPEN (TELAngan PENeng) yang diproduksi oleh Kelompok Wanita Tani (KWT) “Kaki Rinjani”.
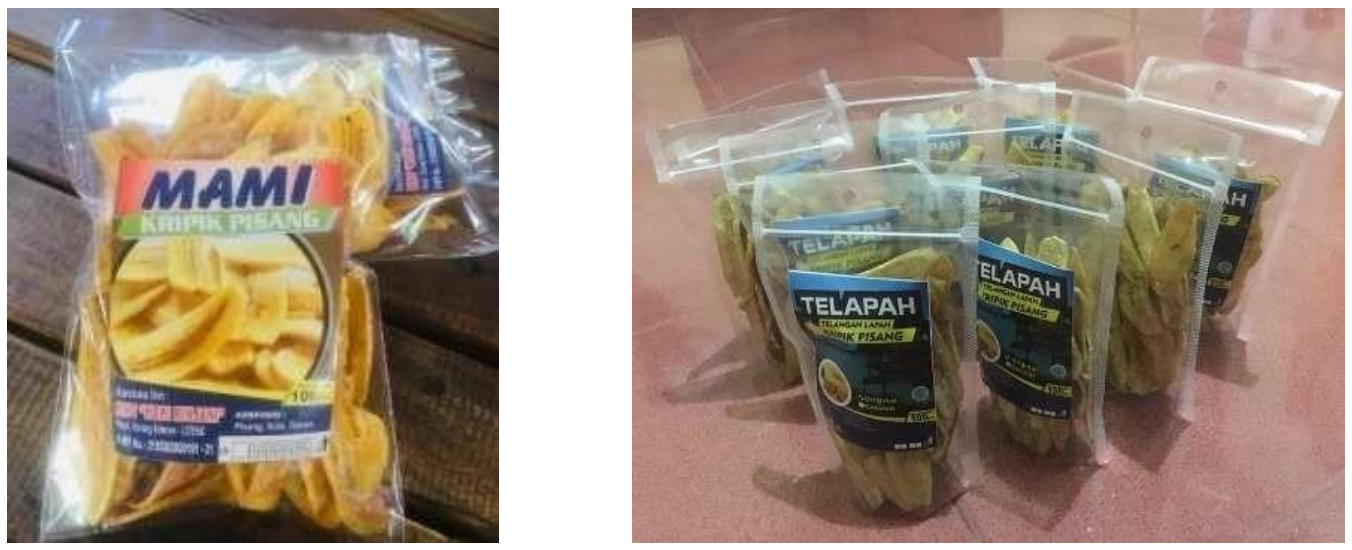

Gambar 5. Perbaharuan Label dan Kemasan Keripik Pisang. Foto Sebelah kiri Label dan Kemasan Lama, Foto sebelah Kanan Label dan Kemasan Baru.

Pemasaran merupakan ujung tombak dari serangkaian kegiatan usaha yang bergerak dalam bidang jasa ataupun barang. Pemasaran juga sangat menentukan apakah usaha yang dijalankan mampu bertahan dan menghasilkan laba atau tidak. Produksi dan pemasaran memiliki keterkaitan yang erat (Putri, Altri dan Ratna, 2012). "

Pada sisi pemasaran keripik, UMKM membangun usaha jaringan dengan warung pengecer, agen di dalam maupun di luar daerah dan menjual langsung pada konsumen. Penjualan dilakukan dengan cara bayar tunda apabila produk habis terjual dan titip jual. Untuk tujuan pemasaran dengan produk berlabel difokuskan pada toko-toko, kantor-kantor langganan seperti kantor KPU dan warung- warung nasi, sedangkan produk tanpa label yang dijual eceran seribu-an ( menggunakan pemanis dan pewarna makanan) dipasarkan diarea lingkungan dan warung-warung kecil

\section{KESIMPULAN}

Hasil dari pelatihan keripik pisang yang diadakan di Desa Karang Sidemen yakni peserta pelatihan dapat mengaplikasiakan kembali tata cara pengolahan keripik pisang yang sesuai dengan standar dari Kelompok Wanita Tani (KWT) "Kaki Rinjani". Langkah ini merupakan salah satu cara pemberdayaan masyarakat khususnya perempuan Desa Karang Sidemen melalui pemanfaatan Sumber Daya Alam (SDA) sehingga dapat meningkatkan perekonomian masyarakat. Meskipun untuk beberapa kelompok baru perwakilan masing-masing dusun Desa Karang Sidemen belum sempat memproduksi karena terkendala sarana dan pra-sarana pengolahan keripik pisang. Harapan kedepannya agar pelatihan lebih lanjut dapat diadakan sehingga dapat memperbaiki kulitas keripik pisang yang dihasilkan dengan kerja sama dengan BUMDES Desa Karang Sidemen serta penyediaan sarana dan pra-sarana bagi setiap kelompok untuk menunjang kelengkapan perlengkapan pengolahan keripik pisang.

\section{UCAPAN TERIMA KASIH}

Ucapan terima kasih disampaikan kepada anggota Kelompok Wanita Tani (KWT) "Kaki Rinjani", dosen pembiimbing lapangan, teman-teman seperjuangan KKN tematik UNRAM Desa Karang Sidemen 2019, perngkat desa Desa Karang Sidemen, serta semua pihak yang membantu dalam pelakssanaan program pemberdayaan masyarakat ini. . 


\section{REFERENSI}

Allahdadi, F., 2011. Women's empowerment for rural development. Dept. of Organizational and Industrial Psychology, Islamic Azad University, Marvdasht Branch. Journal of American Science. Vol 7(1) : 220-229.

Anwar, Suhadi M., Goso dan Adil., 2017. KKN-PPM Penguatan Ekonomi Desa Melalui BUMDES di Desa Poreang Kecamatan Tana Lili Kabupaten Luwu Utara Sulawesi Selatan. Resona Jurnal IImiah Pengabdian Masyarakat. Vol 1(1) : 6-12.

Badan Ketahanan Pangan., 2012. Direktori Pengembangan Konsumsi Pangan. Badan Ketahanan Pangan. Jakarta.

Direktorat Jendral Pembanguanan dan Pemberdayaan Masyarakat Desa. 2016. Kementrian Desa, Pembangunan Daerah Tertinggal dan Transmigrasi. Jakarta Selatan.

Edi Soeharto, Metodologi Pengembangan Masyarakat :Jurnal Comev, Jakarta. BEMJ-PMI, 2004. Vol.I.

Hardono, Gatoet S., 2014. Strategi Pengembangan Diversifikasi Pangan Lokal. Analisis Kebijakan Pertanian. Vol 12(1) : 1-17.

Hasan, Muhammad and Azis, Muhammad (2018) Pembangunan Ekonomi dan Pemberdayaan Masyarakat: Strategi Pembangunan Manusia dalam Perspektif Ekonomi Lokal (Edişi Kedua). CV. Nur Lina Bekerjasama dengan Pustaka Taman IImu, Makassar.

Isbandi Rukminto. 2007. Intervensi Komunitas Pengembangan Masyarkat Sebagai Upaya Pemberdayaan Masyarakat. Jakarta: Raja Grafindo Persada.

Lord, J. dan Hutchison, P., 1993. The process of empowerment: implication for theory and practice. Canadian Journal of Community Mental Health. Vol 12(1) : 5-22.

Nazaruddin M., Zulkarnain, Khaddafi. 2015. Strategi dan Implementasi Pemberdayaan Ekonomi Masyarakat. Jakarta Timur : Ur Press.

Saugi, Wildan dan Sumarno., 2015. Pemberdayaan Perempuan Melalui Pengolahan Bahan Pangan Lokal. Jurnal Pendidikan dan Pemberdayaan Mayarakat. Vol 2(2) : 226-238.

Tahziduhu Ndraha. Pengantar Teori Pengembangan Sumber Daya Manusia. Jakarta : PT Renika Cipta. 2002. 